\title{
Ostectomy versus osteotomy with repositioning of the vestibular cortical in periapical surgery of mandibular molars: A preliminary study
}

\author{
Berta García-Mira ${ }^{1}$, Barbara Ortega-Sánchez ${ }^{2}$, Maria Peñarrocha-Diago ${ }^{3}$, Miguel Peñarrocha Diago ${ }^{3}$
}

\footnotetext{
${ }^{1}$ Associate Professor Master of Oral Surgery and Implantology. University Medical and Dental School. Valencia, Spain

${ }^{2}$ Master of Oral Surgery and Implantology. University Medical and Dental School. Valencia, Spain

${ }^{3}$ Professor of Oral Surgery. Director of the Master of Oral Surgery and Implantology. University Medical and Dental School. Valencia, Spain
}

Correspondence:

Unidad Médico-Quirúrgica

Clínica Odontológica

Gascó Oliag 1

46010 -Valencia-Spain

berta.garcia@uv.es

Received: $11 / 02 / 2009$

Accepted: 23/12/2009

García-Mira B, Ortega-Sánchez B, Peñarrocha-Diago M, Peñarrocha-Diago $\mathrm{M}$. Ostectomy versus osteotomy with repositioning of the vestibular cortical in periapical surgery of mandibular molars: A preliminary study. Med Oral Patol Oral Cir Bucal. 2010 Jul 1;15 (4):e628-32.

http://www.medicinaoral.com/medoralfree $01 / \mathrm{v} 15 \mathrm{i} 4 /$ medoralv15i4p628.pdf

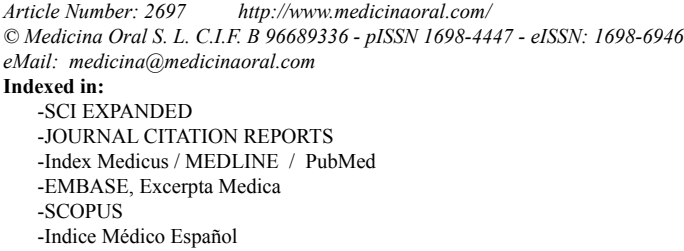

\begin{abstract}
Introduction: Accessing the tooth roots in periapical surgery (PS) requires the elimination of periapical bone.

Objective: To compare the postoperative morbidity and prognosis following PS on mandibular molars by ostectomy, or by osteotomy with repositioning of the vestibular cortical.

Material and Methods: A retrospective clinical study of mandibular molars subjected to PS with ultrasound. Two groups were considered according to the surgical procedure used to access the roots: Group 1 (G1) with ostectomy and Group 2 (G2) with osteotomy and repositioning of the vestibular cortical. Only patients who had properly followed the post-operative instructions, adequately completed the post-operative questionnaires, and with a minimum of 12 months follow-up were included in the study. Post-operative morbidity was evaluated, and a clinical and radiographic follow-up was carried out using the criteria established by von Arx and Kurt in 1999. The SPSS program version 15 for Windows was used, considering values of $\mathrm{p} \leq 0.05$ as statistically significant.

Results: Seventy-five patients, including 18 men and 57 women, with 87 mandibular molars and 107 periapical lesions were subjected to PS. The mean age of the patients was 38.5 years old (range $15-74$ years old). The patients were monitored for an average of 27.2 months (range $12-120$ months). Sixty-six patients (78 teeth) were treated in G1, and 9 patients ( 9 teeth) in G2. There was no relationship between the size of the ostectomy and pain, swelling or prognosis $(\mathrm{p}>0.05)$. Patients who underwent ostectomy presented more swelling than those subjected to osteotomy $(\mathrm{p}<0.05)$. There was no relationship between prognosis and the variables studied $(\mathrm{p}>0.05)$.

Conclusions: There was no statistically significant relationship between the surgical procedure used and postoperative pain or prognosis. Patients who underwent an ostectomy presented more swelling than those who were treated with an osteotomy and repositioning of the vestibular cortical.
\end{abstract}

Key words: Periapical surgery, pain, swelling, mandibular molars, ostectomy, osteotomy. 


\section{Introduction}

In periapical surgery (PS), in order to eliminate the inflammatory apical tissue, form the root-end cavity and achieve proper sealing of the apical foramen with rootend filling (1), it is necessary to eliminate the periapical bone via ostectomy (2). This removal should be the minimum necessary to allow access to the entire lesion and enable visual control of the apices to the affected roots (2).

Due to the greater thickness of the vestibular cortical in this region, access to the mandibular molar root apices requires a large ostectomy, occasionally leaving extensive bone defects.

The aim was to make a preliminary study of the morbidity and prognosis following PS using ostectomy or by osteo-tomy with repositioning of the vestibular cortical.

\section{Material and Methods}

Study sample

Retrospective clinical study of patients undergoing PS between May 1999 and June 2004. Inclusion criteria were mandibular molars apicoectomized using ultrasound, with a minimum follow up of 12 months and adequate completion of the follow-up questionnaires. Patients who did not follow the postoperative instructions were excluded.

Two groups were considered in function of the procedure used to access the teeth apices. Patients in Group 1 (G1) were treated with ostectomy (Fig. 1). Group 2 (Fig. 2) comprised patients treated by osteotomy with
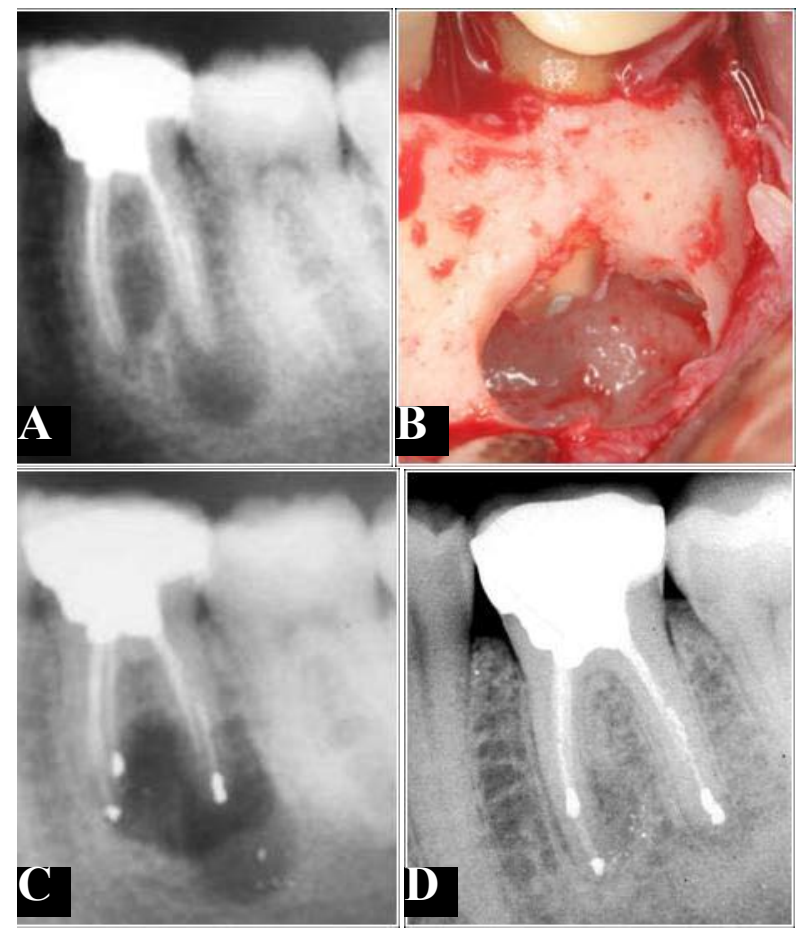

Fig. 1. A. Extraoral panoramic radiograph showing a radiolucent lesion related to the mandibular molar. B. Ostectomy with round tungsten carbide drill to access the tooth roots. C. Radiograph following surgery. D. Follow-up periapical radiograph at 12 months.

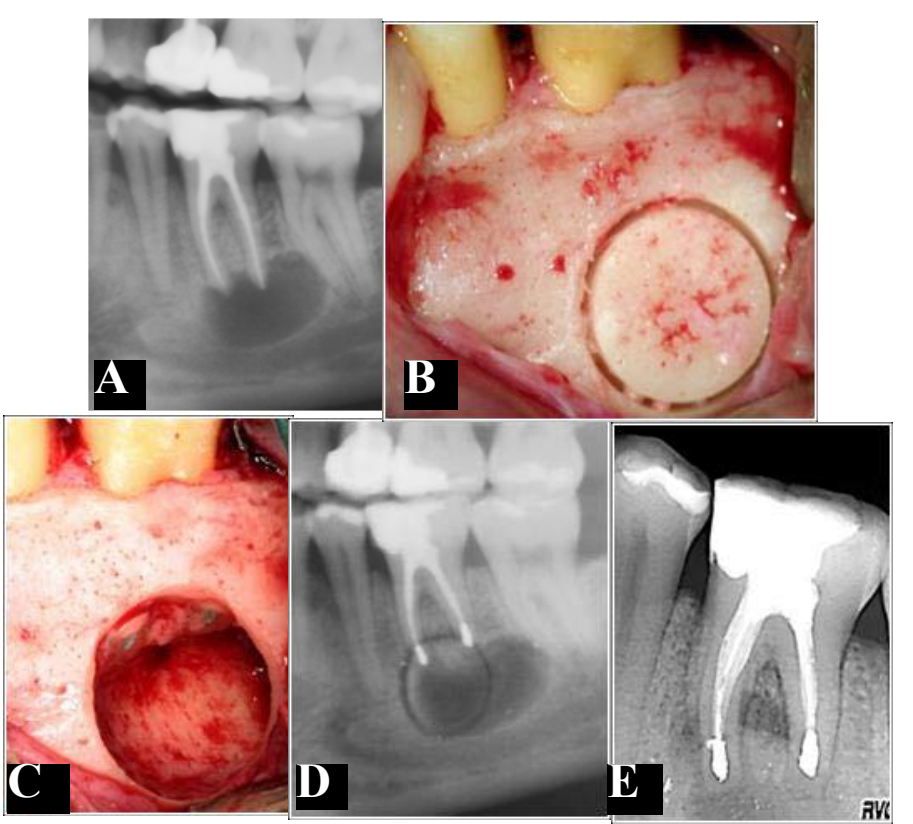

Fig. 2. A. Extraoral panoramic radiograph showing a radiolucent lesion related to the mandibular molar. B. Osteotomy with trephine burr to create the vestibular 'bony lid' and access the tooth roots. C. Root-end filling. D. Radiograph following surgery. E. Follow-up periapical radiograph at 12 months. 
repositioning of the cortical bone when the vestibular cortical was intact and the teeth apices were more than $8 \mathrm{~mm}$ from the mandibular canal. The osteotomy was made creating a bony lid in the vestibular cortical with a trephine burr, which was repositioned following the apicoectomy and root-end filling. This cortical bone is only obtained using the osteotomy technique, and only in these cases is repositioned subsequent to PS.

\section{Surgical procedure}

All operations were carried out by the same surgeon (MPD) under local anesthesia with articaine at $4 \%$ and 1:100,000 adrenaline (Inibsa ${ }^{\circledR}$, Lliça de Vall, Barcelona, Spain). The ostectomy was made using a $0.27 \mathrm{~mm}$ round tungsten carbide drill (Jota ${ }^{\circledR}$, Switzerland) mounted in a handpiece, and abundant irrigation with sterile physiological serum. The osteotomy window was formed using trephine burrs (Straumann ${ }^{\circledR}$ Institute, AG, Basel, Switzerland) and abundant irrigation with sterile physiological serum. The cortical bone was raised with the aid of a surgical hammer and chisel. The bony lid was replaced following apicoectomy and root-end filling. Ultrasound tips for periapical surgery (Piezon ${ }^{\circledR}$ Master 400, EMS ${ }^{\circledR}$ Electro Medical Systems S.A, Switzerland) were used to form the root-end cavity, root-end filling was made with zinc-free silver amalgam (Non-gamma $2 \circledR$ Tytin ${ }^{\circledR}$, Kerr, USA). All patients were prescribed the same postoperative medication: amoxicillin (Clamoxyl ${ }^{\circledR}$, GlaxoSmithKline, S.A, Madrid, Spain) 500 $\mathrm{mg} / 8$ hours for 7 days; ibuprofen (Bexistar ${ }^{\circledR}$, Laboratorio Bacino, Barcelona, Spain) $600 \mathrm{mg} / 8$ hours for 3 days, and mouthwash with chlorhexidine at $0.12 \%$ (GUM ${ }^{\circledR}$, John O. Butler Co, Chicago, USA) 3 times a day for 7 days.

Patients were instructed not to smoke during the first postoperative week, and to brush 3 times a day after the first 24 hours.

\section{Data collection}

The number of operated teeth and lesions was recorded. During surgery, the size of the ostectomy and osteotomy was measured using a digital caliper calculating the largest and smallest diameters; the sizes were classified as: less than $1 \mathrm{~cm}^{2}$, between 1 and $2 \mathrm{~cm}^{2}$, and greater than $2 \mathrm{~cm}^{2}$.

The perceived postoperative pain was recorded on a 4-point descriptive scale (3), (1 - absence of pain; 2 slight; 3 - moderate; 4 - intense pain). Swelling was recorded as 1 - absent (no swelling); 2 - slight (intraoral swelling at the operated area); 3 - moderate (moderate intraoral swelling at the operated area); 4 - intense (intensive extraoral swelling extending beyond the operated area). The values for pain and swelling were recorded by each patient 2, 4, 6 and 12 hours after surgery, and on each of the 7 postoperative days.

One week after surgery the patient was examined and the sutures removed. The appearance of any postoperative complications such as hematoma, wound opening, infection or postoperative neuropathy was noted.

Success was determined by panoramic radiographic study using a digital orthopantomograph OP100®. The resulting image was calibrated using the CliniView ${ }^{\circledR}$ program Version 5.1 (Instrumentarium Imaging, Tuusula, Finland) and introduced into an image analyzer, MicroImage Pro-Plus ${ }^{\circledR}$ (MediaCybernetics, Inc; Silver Spring, USA).

Evolution was evaluated at 6 and 12 months of surgery according to the criteria of von Arx and Kurt (4), classified as: 1 - failure; 2 - improvement; 3 - success. It was also noted if the tooth remained in the mouth, being classified as either a functional or nonfunctional tooth (if the tooth had been extracted) (5). Statistical study

The SPSS v15 program for Windows was used, making a descriptive analysis of each of the variables. A mixed ANOVA study with 2 factors was made. Statistical significance was considered for values of $p \leq 0.05$.

\section{Results}

Eighty-nine patients underwent PS on mandibular molars between May 1999 and June 2004. Six patients were excluded from the study for non-completion of the pain and swelling scales, six for not following the postoperative indications and 2 for having an incomplete follow up (less than 12 months). Seventy-five patients, with 87 mandibular molars, 107 lesions and 200 canals were included in the study. The mean age of the patients was 38.5 years (range 15-74 years); 18 men and 57 women were operated upon. The patients were followed for a mean of 27.2 months (range 12-120 months). The number of patients, lesions, affected teeth and the size of bone recession with respect to the surgical technique employed is shown in table 1.

Postoperative complications were observed in 5 patients with hematoma (all in G1), and in 3 patients with suture dehiscence (2 in G1 and 1 in G2). One patient had a postoperative infection and another had a transitory

Table 1. $\mathrm{N}^{\mathrm{o}}$ of patients, lesions, teeth and size by ostectomy and osteotomy.

\begin{tabular}{|l|c|c|c|c|c|c|}
\hline & \multirow{2}{*}{$\mathrm{N}^{\mathrm{*}}$ patients } & \multirow{2}{*}{$\mathrm{N}^{\mathrm{o}}$ lesions } & \multirow{2}{*}{$\mathrm{N}^{\mathrm{*}}$ teeth } & \multicolumn{3}{|c|}{ Size } \\
\cline { 5 - 7 } & & & & $<1 \mathrm{~cm}$ & $1-2 \mathrm{~cm}$ & $>2 \mathrm{~cm}$ \\
\hline Ostectomy & 66 & 98 & 78 & 49 & 44 & 5 \\
\hline Osteotomy & 9 & 9 & 9 & 4 & 5 & - \\
\hline
\end{tabular}


mental neuropathy (both in G1). There was no relationship between postoperative complications and prognosis in PS $(\mathrm{p}>0.05)$.

Figure 3 shows the evolution of postoperative pain and swelling in G1 and G2. It was observed that patients undergoing osteotomy had a more distinct peak of pain and swelling. Patients in G1 perceived maximum pain during the first 48 hours, while in G2 pain increased to a maximum on day 2 . Swelling evolved similarly in $\mathrm{G} 1$ and $\mathrm{G} 2$; increasing progressively until reaching a maximum on the second day. There was no statistically significant relationship between the size of the ostectomy and osteotomy with either pain or swelling $(\mathrm{p}<0.05)$. Table 2 illustrates that patients subjected to ostectomy (G1) presented greater postoperative swelling than patients with osteotomy $(\mathrm{G} 2)(\mathrm{p}=0.02)$. There was no statistically significant difference in perceived pain between the two groups ( $\mathrm{p}>0.05)$.

Regarding prognosis, at 6 months follow-up the success rate was higher in patients undergoing osteotomy with repositioning of the vestibular cortical (G2) against ostectomy (G1), this result was inverted at 12 months (Table 3); the differences were not statistically significant in either case. At 12 months, $94.2 \%$ of teeth were considered functional, and 5 teeth had been extracted (all in G1).
A. PAIN

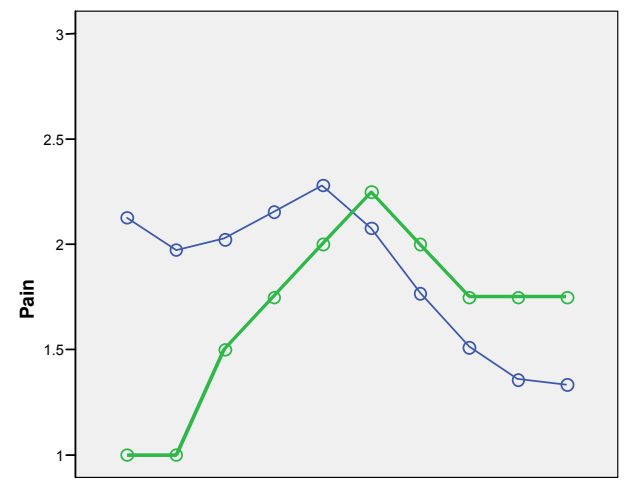

G1: Ostectomy

G2: Osteotomy
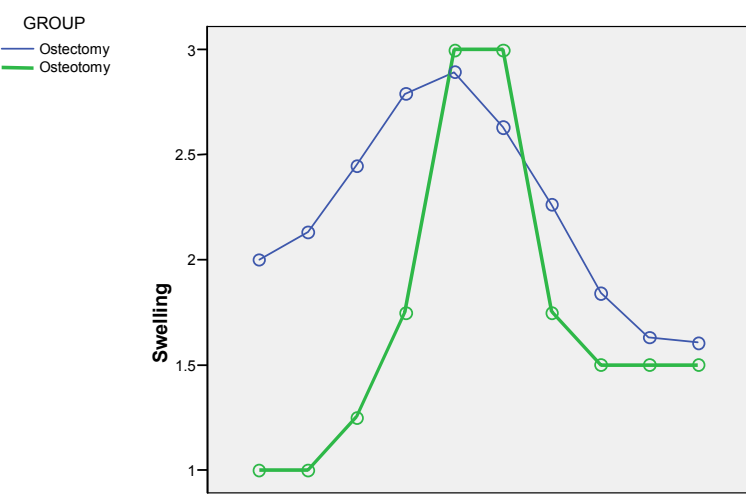

G1: Ostectomy

G2: Osteotomy

Fig. 3. Interrelation between pain (A) and swelling (B) in function of osteotomy and ostectomy.

Table 2. Relation of ostectomy and osteotomy with pain, swelling and prognosis.

\begin{tabular}{|l|c|c|c|c|c|c|}
\hline \multirow{2}{*}{} & \multicolumn{2}{|c|}{ PAIN } & \multicolumn{2}{c|}{ SWELLING } & \multicolumn{2}{c|}{ PROGNOSIS } \\
\cline { 2 - 7 } & $\mathrm{F}$ & $\mathrm{p}$ & $\mathrm{F}$ & $\mathrm{p}$ & $\mathrm{F}$ & $\mathrm{p}$ \\
\hline Ostectomy versus osteotomy & 0.254 & 0.617 & 3.152 & 0.020 & 0.393 & 0.533 \\
\hline
\end{tabular}

Table 3. Overall evolution at 6 and 12 months following the criteria of von Arx and Kurt (9) in \%.

\begin{tabular}{|c|c|c|c|c|c|c|c|}
\hline & \multicolumn{3}{|c|}{6 months } & \multicolumn{3}{|c|}{12 months } & \multirow{2}{*}{$\begin{array}{c}\mathrm{N}^{\mathrm{o}} \text { func- } \\
\text { tional } \\
\text { teeth }\end{array}$} \\
\hline & Success & $\begin{array}{c}\text { Improve- } \\
\text { ment }\end{array}$ & Failure & $\begin{array}{l}\text { Suc- } \\
\text { cess }\end{array}$ & Improvement & Failure & \\
\hline Ostectomy (G1) & $\begin{array}{c}34.6 \\
(n=27)\end{array}$ & $\begin{array}{c}46.1 \\
(\mathrm{n}=36)\end{array}$ & $\begin{array}{c}19.3 \\
(n=15)\end{array}$ & $\begin{array}{c}59.0 \\
(n=46)\end{array}$ & $\begin{array}{c}27.9 \\
(n=22)\end{array}$ & $\begin{array}{c}13.1 \\
(n=10)\end{array}$ & 73 \\
\hline Osteotomy (G2) & $\begin{array}{c}33.3 \\
(\mathrm{n}=3)\end{array}$ & $\begin{array}{c}55.6 \\
(\mathrm{n}=5)\end{array}$ & $\begin{array}{c}11.1 \\
(\mathrm{n}=1)\end{array}$ & $\begin{array}{c}55.6 \\
(\mathrm{n}=5)\end{array}$ & $\begin{array}{c}33.3 \\
(\mathrm{n}=3)\end{array}$ & $\begin{array}{c}11.1 \\
(\mathrm{n}=1)\end{array}$ & 9 \\
\hline Overall & $\begin{array}{c}34.5 \\
(n=30)\end{array}$ & $\begin{array}{c}46.0 \\
(n=40)\end{array}$ & $\begin{array}{c}19.5 \\
(\mathrm{n}=17)\end{array}$ & $\begin{array}{c}58.4 \\
(\mathrm{n}=51)\end{array}$ & $\begin{array}{c}29.0 \\
(\mathrm{n}=25)\end{array}$ & $\begin{array}{c}12.6 \\
(\mathrm{n}=11)\end{array}$ & 82 \\
\hline
\end{tabular}




\section{Discussion}

In the osteotomy group, pain peaked at a maximum on the second day, while in the ostectomy group pain remained level during the first 48 hours. Kvist et al. (6) also found maximum pain during the first 24 postoperative hours. Regarding perceived swelling, a maximum peak was found on the 2 nd postoperative day; similar to results obtained by García et al. (7) after operating on 102 patients. Patients undergoing ostectomy presented greater swelling during the postoperative period than the patients with osteotomy and repositioning of the vestibular cortical.

Although the success rate of PS on mandibular molars was $58.4 \%$ after 12 months follow-up, a high number of teeth remained in the mouth $(94.5 \%)$; similar to results obtained by Peñarrocha et al. (8), who achieved 90.4\% clinical and 54.8\% radiographic healing after operating on 31 mandibular molars. Rud et al. (9) on 834 mandibular molar roots obtained $92 \%$ complete healing, 1\% uncertain and 7\% failure; while von Arx et al. (10) found a $94 \%$ success rate in 16 mandibular molars.

Ostectomy was used to access the tooth roots in the majority of the lesions (91.6\%). Osteotomy allows the repositioning of the vestibular cortical after surgery, but brought no benefits in the few cases of this preliminary study.

\section{References}

1. Peñarrocha M, Martí E, García B, Gay C. Relationship of periapical lesion radiologic size, apical resection, and retrograde filling with the prognosis of periapical surgery. J Oral Maxillofac Surg. 2007;65:1526-9.

2. von Arx T, Walker WA 3rd. Microsurgical instruments for rootend cavity preparation following apicoectomy: a literature review. Endod Dent Traumatol. 2000;16:47-62.

3. Yoldas O, Topuz A, Isçi AS, Oztunc H. Postoperative pain after endodontic retreatment: single- versus two-visit treatment. Oral Surg Oral Med Oral Pathol Oral Radiol Endod. 2004;98:483-7.

4. von Arx T, Kurt B. Root-end cavity preparation after apicoectomy using a new type of sonic and diamond-surfaced retrotip: a 1-year follow-up study. J Oral Maxillofac Surg. 1999;57:656-61.

5. Friedman S. The prognosis and expected outcome of apical surgery. Endod Topics. 2005;11:219-62.

6. Kvist T, Reit C. Postoperative discomfort associated with surgical and nonsurgical endodontic retreatment. Endod Dent Traumatol. 2000;16:71-4

7. García B, Penarrocha M, Martí E, Gay-Escodad C, von Arx T. Pain and swelling after periapical surgery related to oral hygiene and smoking. Oral Surg Oral Med Oral Pathol Oral Radiol Endod. 2007;104:271-6.

8. Penarrocha Diago M, Sanchis Bielsa JM, Gay Escoda C. Periapical surgery of 31 lower molars based on the ultrasound technique and retrograde filling with silver amalgam. Med Oral. 2001;6:376-82.

9. Rud J, Rud V, Munksgaard EC. Periapical healing of mandibular molars after root-end sealing with dentine-bonded composite. Int Endod J. 2001;34:285-92.

10. von Arx T, Gerber C, Hardt N. Periradicular surgery of molars: a prospective clinical study with a one-year follow-up. Int Endod J. 2001;34:520-5. 